\title{
Zusammen sind wir stark
}

Redaktionsteam der Schweizerischen Ärztezeitung

Interprofessionalität ist aus dem Gesundheitswesen nicht mehr wegzudenken. Eine enge Zusammenarbeit auf Augenhöhe zwischen ärztlichen Fachpersonen und Vertreterinnen und Vertretern anderer Gesundheitsberufe bildet einen wichtigen Eckpfeiler, um den grossen Herausforderungen des Gesundheitssystems, wie beispielsweise dem Fachkräftemangel oder der immer komplexer werdenden Patientenversorgung, begegnen zu können.

Wir beleuchten in einer Artikelserie die verschiedenen Facetten der Interprofessionalität. Den Start macht in dieser Ausgabe Eberhard Wolff mit seinem Beitrag "Aus der Vorgeschichte der Interprofessionalität». Der Medizinhistoriker zeigt in seinem Artikel auf, welche Entwicklungen die vormals streng hierarchisch geprägte $\mathrm{Zu}$ sammenarbeit zwischen Pflegepersonal und Ärzten (der Anteil der Ärztinnen war dazumal noch schwindend klein) langsam, aber stetig hin zu einem Teamwork mit entsprechendem Fachwissen und gegenseitigem Respekt begünstigten.

In den nachfolgenden Ausgaben gehen wir un-

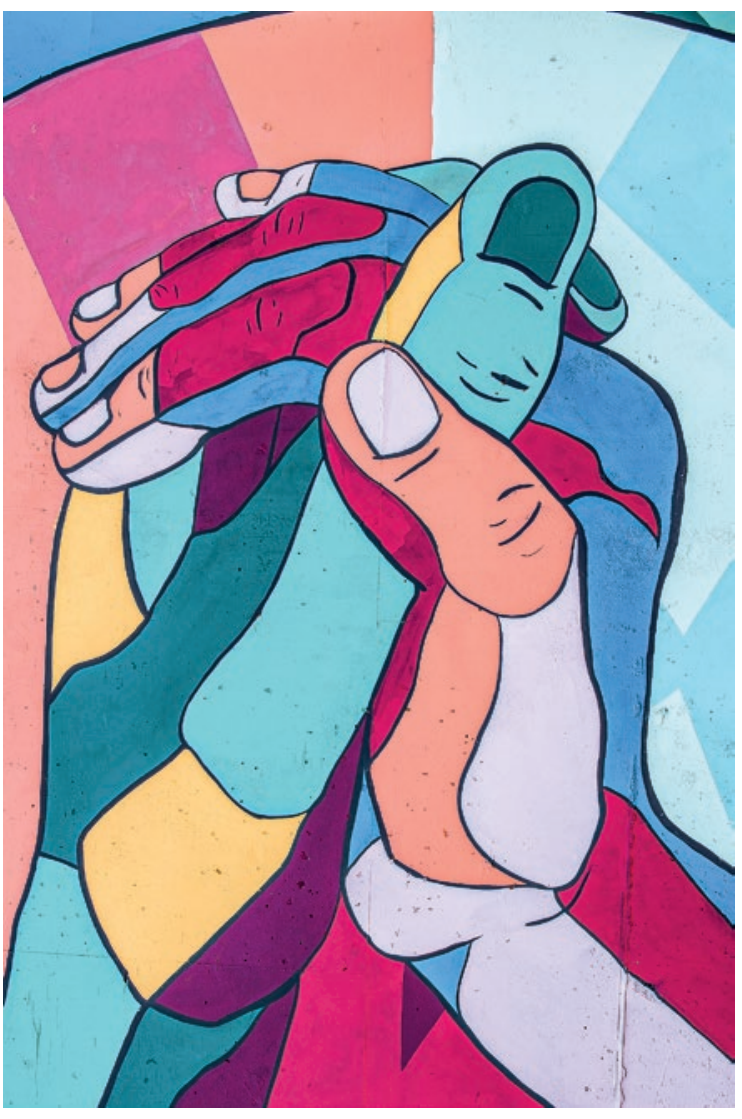

gnostik und Medizin steht. Dabei wagen wir auch einen Blick über die Landesgrenzen. Konkret berichten Gesundheitsfachleute aus Kanada, wie sich ihr Berufsalltag dank der gut etablierten Interprofessionalität verändert hat.

Wir möchten diese Themenserie bewusst nicht bloss auf Studienresultate und Analysen beschränken, sondern auch ganz nahe auf «die gelebte Zusammenarbeit» zoomen: sei es in der Aus- und Weiterbildung oder im Alltag im stationären und ambulanten Bereich.

Als Schweizerischer Ärzteverlag leben auch wir eine enge Zusammenarbeit vor allem hinsichtlich unserer Publikationen. Verschiedene Autorinnen und Autoren vertiefen in der Dezemberausgabe der Zeitschrift Primary and Hospital Care das Thema der Schnittstellen von interdisziplinären und interprofessionellen Teams.

Damit können wir unseren Leserinnen und Lesern auf Anfang des nächsten Jahres ein interessantes und breit gefächertes Themendossier zum Thema «Interprofessionalität» zur Verfügung stellen.

Nun wünschen wir Ihnen viel Vergnügen bei der Leknach, wie die interprofessionelle Zusammenarbeit ein Garant für den Zugang zur medizinischen Grundversorgung in peripheren Regionen sein kann und wo die Schweiz in Sachen berufs- und sektorenübergreifende Zusammenarbeit von Fachpersonen aus Pflege, Dia- türe des Auftaktartikels zu dieser Serie auf Seite 1537 und der Beiträge in den kommenden Ausgaben.

Bildnachweis

Tim Mossholder / Unsplash 